\title{
A ANÁLISE DE TENDÊNCIAS E DA CULTURA COMO UMA FERRAMENTA PARA A GESTÃo DE MARCAS.
}

\section{THE ANALYSIS OF TRENDS AND CULTURE AS A TOOL FOR BRAND MANAGEMENT.}

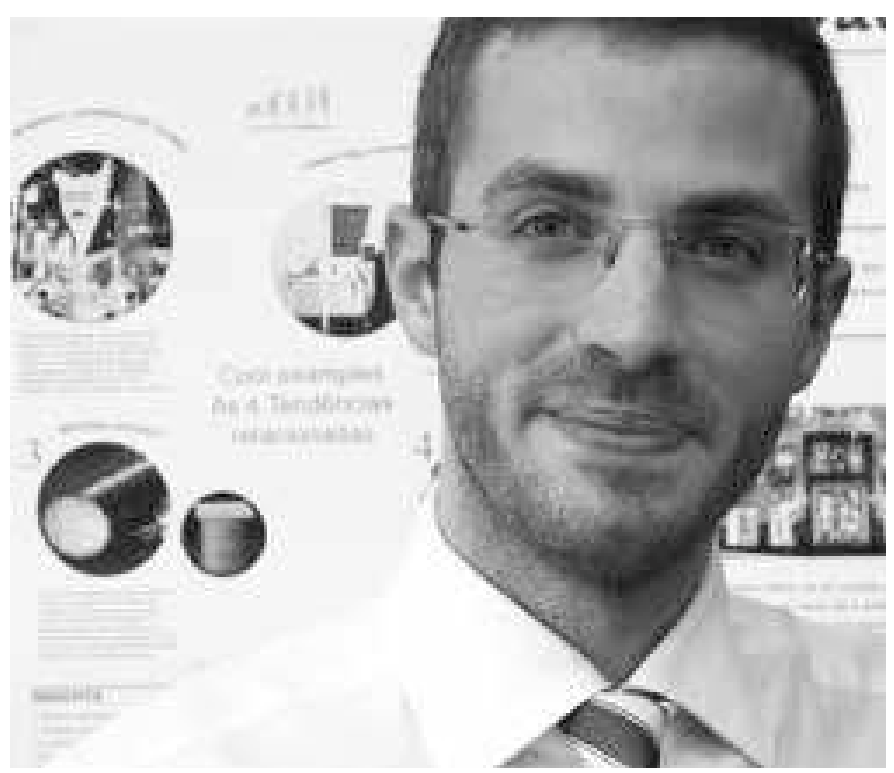

\section{Nelson Pinheiro Gomes}

Doutor na Especialidade de Cultura e Comunicação pela Universidade de Lisboa.

Docente no Programa de Cultura e Comunicação da Faculdade de Letras da Universidade de Lisboa.

nelsonpinheiro@campus.ul.pt

\section{RESUMO}

Os estudos de tendências abordam os comportamentos e os padrões de consumo, de estilo e de gosto numa perspetiva de análise cultural e de mentalidades que ajuda a compreender o consumidor e a delinear estratégias mais informadas e sólidas. Considerando a importância e a dificuldade crescente em compreender, identificar e gerir segmentos e grupos sociais, este artigo sublinha a importância da análise de tendências na construção e gestão de uma marca perante os seus públicos.

\section{PALAVRAS-CHAVE}

Branding. Tendências. Cultura. 


\section{ABSTRACT}

Trends studies dwell on consumer behaviors and patterns, as well as style and taste, on a cultural and mindset perspective that helps to better understand the consumer and to set more solid and informed strategies. Considering the growing importance and difficulty in understanding, identifying and managing segments and social groups, this paper underlines the importance of trends analysis for the construction and management of a brand before its audience.

\section{KEYWORDS}

Branding. Trends. Culture.

\section{INTRODUÇÃO}

O branding, como disciplina do marketing, tem sido objeto de estudo numa abordagem estratégica que integra vários componentes da gestão com as ciências do consumo. Esta disciplina tem exigido um esforço de descodificação do papel da marca (KAPFERER, 2004; AAKER, 1991) e de compreensão das mutações na sociedade que obrigam a uma revisão das práticas e dos próprios conceitos associados à gestão de marcas. Todavia, permanece ainda muito por explorar o papel e as exigências da marca num contexto e num espaço cultural com características e padrões de comportamento próprios. A mente coletiva dá origem a tendências emergentes que, por sua vez, dão lugar a necessidades e comportamentos específicos face a determinadas narrativas, serviços e artefatos. Neste sentido, importa integrar as visões de Michael Solomon (1999), sobre a cultura de consumo, e de Jean Kapferer (2001) e David Aaker (1991) com novas abordagens e descobertas na área dos estudos de tendências, foco em tendências no comportamento de consumo, utilizando como base conceptual as obras de Henrik Vejlgaard (2008) e de William Higham (2009). $\mathrm{O}$ artigo foi concebido de modo a partir de temas introdutórios para a sua problematização prática, identificando, como objetivo principal, práticas e temas emergentes no branding. O primeiro ponto do artigo apresenta as principais problemáticas dos estudos de tendências e do coolhunting, sublinhando a complexidade do contexto sociocultural e os padrões de mentalidade que estão a desenvolver-se no século XXI. O último tópico 
do artigo problematiza a aplicação dos estudos de tendências e da análise cultural no âmbito da gestão de marcas. Estes temas emergentes articulamse de forma a demonstrar a importância da análise do zeitgeist atual e do seu impacto no consumidor e nas práticas de gestão. Isto obriga a uma atualização da visão sobre o sistema e os processos sociais, de modo a gerar melhores práticas na gestão das marcas.

\section{ESTUDOS DE TENDÊNCIAS E COOLHUNTING}

Conforme adverte Luís Rasquilha, as tendências são por vezes consideradas algo etéreo devido ao seu elevado grau de intangibilidade e dificuldade de identificação e estudo, sendo difíceis de entender e de percecionar em termos do seu real valor de aplicação (RASQUILHA, 2011, p. 10). Contudo, as tendências são uma fonte de inegável valor para as empresas, para as marcas e para a estratégia.

As tendências são o reflexo da nossa vivência em sociedade, produto da civilidade, dos valores, dos desejos e do contexto económico e sociocultural. Henrik Vejlgaard (2008) estudou em profundidade a questão das tendências e desenvolveu uma sólida teoria de base para o desenvolvimento dos estudos desta área. Segundo o autor, para um sociólogo de tendências, uma tendência não é algo que aconteceu, mas sim uma previsão de algo que vai ocorrer de uma certa forma e que será aceite pela população em geral (VEJLGAARD, 2008, p. 7).

Atualmente, as tendências desenvolvem-se num ciclo acelerado. Contudo, o processo e a natureza das tendências permanecem idênticos. Uma tendência é um processo que regista uma mudança comportamental que está assente em mentalidades emergentes e que é suportado, posteriormente, em interpretações que podem gerar pistas estratégicas. Por outras palavras, todas as tendências pressupõem uma alteração e um desenvolvimento profundos no gosto e no estilo que permeiam o nosso quotidiano (GOMES e FRANCISCO, 2013). Não obstante, é necessário cuidado ao definir a palavra e o seu sentido no mundo atual, especialmente no que diz respeito ao meio empresarial e aos estudos de tendências.

Henrik Vejlgaard (2008) acrescenta que o desenvolvimento de uma tendência é um dos mistérios por resolver do nosso quotidiano. $O$ enredo começa com uma ou mais pessoas que desenvolvem um produto/serviço 
novo. Todavia, o elemento mais importante diz respeito a um grupo variado de pessoas, denominados por trendsetters (VEJLGAARD, 2008, p. 5), ou seja, aqueles indivíduos que asseguram a primeira disseminação e validação de uma tendência e do seu objeto, promovendo os mesmos perante os seus pares.

Com os estudos de tendências, e através do desenvolvimento da análise dos comportamentos de consumo, as tendências começam a distanciar-se da moda e refletem agora todos os nossos comportamentos sociais. Uma tendência, funcionando como um reflexo das nossas mentalidades, representações e práticas, está sujeita a um macro contexto cultural composto por variados elementos históricos, filosóficos, espirituais, tecnológicos, económicos, demográficos e políticos. A tendência é um reflexo do zeitgeist, das nossas aspirações, crenças, vontades e desejos. Desta forma, as tendências não estão limitadas ao design e ao estilo; elas também afetam o que comemos e bebemos, o que lemos, os filmes que queremos ver, entre outros.

Conforme sugerido por Henrik Vejlgaard (2008, p. 20), ao olharmos para as alterações na tecnologia, na política, na economia e na cultura, podemos argumentar que as mudanças nestas áreas ocorreram num determinado período de tempo, pois se fossem rápidas poderíamos chamá-las de revoluções. Neste cenário, estamos perante tendências, ou seja, alterações nas mentalidades e nos comportamentos que se prolongam no tempo e que afetam grande parte da população. Uma coisa é certa: o estilo e o gosto mudam de tempos a tempos. As alterações podem não ser óbvias ou envolver vários fatores. Todavia, na medida em que podemos compreender o comportamento humano, também podemos compreender e explicar as tendências.

É importante nesta altura diferenciar um cool example e uma manifestação de tendência da própria Tendência. A empresa e rede de coolhunting Science of the Time refere que um cool example é um exemplo de uma tendência com as seguintes características: atrativo, inspirador e com potencial de conhecimento (Science of the time, 2015). Peter Gloor, Jonas Krauss e Stefan Nann referem-se à natureza do cool da seguinte maneira:

Nós definimos "coolness" como um elemento que combina quatro características. Primeiro, as coisas cool são novas. [...] Segundo, as 
coisas cool tornam-nos parte de uma comunidade, elas ajudam-nos a estar integrados com os nossos pares. [...] Terceiro, as coisas cool são giras. Ter um iPhone é giro, uma vez que parece ser tão bem concebido e cool. [...] Quarto, as coisas cool trazem sentido para a nossa vida. As coisas cool tornam as pessoas mais felizes. (Gloor et al, 2009, p. 1-2) [1]

William Higham (2009, p. 153) acrescenta que existe um ciclo, na medida em que o consumidor A comporta-se de um certo modo; os consumidores $B$ e $C$ observam e copiam o consumidor $A$; depois, os consumidores $W, X, Y$ e $Z$ copiam os consumidores $B$ e $C$ num processo conhecido como a difusão da tendência.

Luís Rasquilha (2011) sugere que as tendências podem ser divididas em duas grandes categorias: macro ou micro. As macro tendências, normalmente, são as mais poderosas; influenciam uma série de sectores, mercados e demografia. Estas tendências são direcionadas para atitudes e necessidades dos consumidores. As micro tendências manifestam-se num número reduzido de consumidores. São tipicamente regionais ou nacionais e são normalmente direcionadas para um determinado sector ou comportamento. Fornecem pistas para as macro - que são manifestações antecipadas (RASQUILHA, 2011, p. 17). William Higham (2009, p.87) acrescenta que com tempo é possível que uma micro tendência ganhe espaço e se transforme numa macro tendência.

Para além destas duas categorias, podemos também incluir as tendências fundacionais, ou paradigmas, ou seja, tendências que operam num nível mais profundo na sociedade e que influenciam todo o nosso quotidiano e mentalidade. $\mathrm{O}$ problema com os paradigmas e as macro tendências é que elas possuem uma influência duradoura na sociedade e, devido à sua grande complexidade, são difíceis de investigar.

Henrik Vejlgaard (2008) desenvolveu o Modelo Diamante que categoriza a apropriação de uma tendência pela sociedade. O modelo foi criado para o estudo da moda nos anos 1990. Todavia, o autor adaptou o mesmo modelo para o estudo das tendências, de modo a poder analisar a interação de grupos de indivíduos com os objetos das tendências, oriundos de vários setores. Henrik Vejlgaard analisa os vários grupos presentes no modelo diamante:

Os Trendsetters são os indivíduos mais abertos e curiosos no que diz 
respeito ao estilo e ao gosto [...] Os Trend followers são um pouco como os trendsetters, mas precisam de ver outras pessoas a utilizar os estilos inovadores antes de os adotarem eles mesmos [...] Os Early Mainstreamers aceitam os novos estilos um pouco antes da maioria [...] Os mainstreamers estão no centro do esquema de aceitação dos estilos novos e inovadores [...] Os conservadores preferem estilos que já existem há anos ou até décadas. Eles são os mais céticos face a novos estilos. [2] (VEJLGAARD, 1998, p. 71-72)

Importa também considerar a importância da Curva S, ou seja, para se obter a penetração máxima no mercado, uma tendência necessita percorrer estes grupos atrás referidos, de forma a que possa ser aceite pelos vários perfis de adoção da tendência. Malcolm Gladwell apresenta a questão da curva na sua obra, sublinhando o momento em que a tendência "explode", ou seja, o tipping point (GLADWELL, 2006), que se encontra entre os trend followers e a early majority.

Após a aceitação por parte dos inovadores e dos primeiros adotantes, as manifestações da tendência sofrem uma explosão em número e relevância, expandindo-se por vários grupos ou pela sociedade em geral. No fim, os últimos a adotar são os conservadores que demoram muito mais tempo do que os restantes, atribuindo ao esquema a sua figura em " $S$ ".

A análise de tendências, como já referimos, possui uma aplicação prática que tem sido crescentemente utilizada por consultoras e por várias redes como a TrendHunter, a Science of the Time, a TrendWatching, a Brain Reserve, a Trends Active, a Trend Wolves, a AYR Consulting, entre muitas outras. Conforme Luís Rasquilha (2011, p. 12) sugere, a análise sistemática de padrões de mudança evita que as empresas recuem no mercado e fornece inegáveis insights para que as empresas se adaptem para mudar formas de atuação, identificando e marcando os novos mercados.

Com um interesse crescente por estilo e pelo gosto, é necessário compreendermos como avaliar e como identificar tendências. Um dos elementos-chave prende-se com as observações de sinais que revelam que certos aspetos do comportamento estão a sofrer alterações - sinais que na maioria das vezes podem ser pouco óbvios. À medida que o tecido empresarial toma consciência da importância das tendências, cresce a necessidade de compreender como podem ser aplicadas. 
Um analista de tendência usa as pistas que tira da observação dos comportamentos sociais, e de uma monitorização permanente dos media, dos locais de consumo, das correntes artísticas e estéticas, da mutações nos estilos de vida e na moda, nas migrações, nas relações sociais, entre outras áreas. $O$ estudo e a análise destas informações podem fornecer pistas relevantes que podem ser aplicadas nas empresas e revelar oportunidades, recursos e potencialidades. Conforme William Higham revela:

A velocidade das mudanças nos produtos e no consumidor, a indistinção nos limites das tradicionais demografias, o aumento do poder do consumidor e a globalização estão a tornar a determinação de tendências uma necessidade. As tendências podem ajudar as empresas a compreender o seu mercado em tempos de mudança.[3] (HIGHAM, 2009, p. 17)

No processo de identificação e análise de tendências, importa considerar e observar os comportamentos dos indivíduos no seu habitat natural. Porém, para tal, é necessário uma estrutura conceptual que distinga as manifestações e os objetos das tendências das quais derivam. A compreensão de elementos culturais e sociais torna-se necessária para fornecer as informações empíricas necessárias para discernir a natureza e o peso das várias manifestações de tendências, tal como novos produtos, serviços, comportamentos, estilos e representações. O coolhunter é o indivíduo capaz de identificar e de separar conceptualmente o padrão, ou seja a tendência, das várias formas através das quais ela se torna visível e presente na sociedade. O coolhunter monitora a renovação de símbolos e exerce uma perspetiva crítica na observação da mudança nas práticas de consumo de cada tribo. Por norma, são indivíduos com gostos e visões vanguardistas e com um espírito aberto a novas correntes e inovações. $O$ analista de tendências, tal como o coolhunter, também estuda as tendências, mas numa perspetiva mais profunda, na medida em que está responsável por recolher as observações do coolhunter e analisar os padrões presentes nos mesmos, gerando pistas de inovação. $O$ analista de tendências é o indivíduo com competências para identificar tendências e gerar um quadro mais desenvolvido sobre as principais alterações na sociedade (GOMES e FRANCISCO, 2013).

O marketeer e o estratega, em articulação com o coolhunter ou o 
analista de tendências, utilizam as informações decorrentes da análise das manifestações de tendências, de modo a conceber estratégias de sucesso. Para tal, importa não só identificar e analisar tendências, bem como seguir e estudar os interesses e os comportamentos dos trendsetters e dos indivíduos que os seguem. $\mathrm{O}$ acompanhamento das alterações nas mentalidades e nos comportamentos permite a gestão de políticas eficientes e bem-sucedidas para as áreas do marketing, do branding e da estratégia.

\section{TENDÊNCIAS, CULTURA E GESTÃO DE MARCAS}

Desde os finais do século XX, tornou-se necessário criar uma nova visãoe desenvolver investigação sobre o comportamento de consumo transcultural. Apesar de estarmos perante novos tipos de padrões de comportamento e de consumo, como vimos anteriormente, que afetam o estilo e o gosto, bem como as relações sociais, a investigação neste campo ainda se encontra numa fase embrionária, tal como a sua capacidade de aplicação prática nos negócios. Apenas recentemente, as marcas e as empresas começam a prestar a devida atenção a estas novas áreas de investigação e às novas atitudes de consumo.

Estas novas mentalidades e padrões de comportamento social alteraram a forma de fazer negócios e de observar as interações sociais. As tendências são um elemento de crescente importância neste mundo em alteração, pelo que a sua aplicação eficiente perante o mercado, as empresas e a sociedade em geral, depende de vários elementos e ferramentas. Cada tendência opera no nível da mentalidade, gerando um imaginário comum constituído por um conjunto de ideias, representações, referências e práticas, cuja descodificação pode tornar-se num importante instrumento para a implementação de políticas sociais, empresariais, culturais, entre muitas outras.

As profundas alterações na sociedade, como o advento da globalização, as migrações e o crescente desenvolvimento tecnológico e comunicacional, causaram mutações, ou uma revisão, dos comportamentos de consumo do século XX. Atualmente, com a multiplicidade de ideias e de visões, o marketing não pode oferecer apenas uma revisitação do passado, criando elementos de identificação e de preservação de identidades. $O$ marketing deve agora apresentar um discurso orientado para a transparência 
dos benefícios do produto/serviço e capaz de se adaptar à rápida alteração nos comportamentos em momentos e espaços específicos. A identificação de características culturais num determinado produto pode ser atrativa para certas comunidades, mas detrativa para outras que não se identificam com esse discurso.

Perante uma hipermodernidade (LIPOVETSKY, 2006) onde as estruturas e os comportamentos sofrem alterações de uma forma muita rápida, dando lugar à ideia de fluidez, é importante que, tal como Jean Kapferer (2001) sugere, a gestão de marcas ganhe novas visões e se liberte das práticas mais antigas e clássicas. O próprio mercado de consumo é um espaço com crescentes mutações e a gestão está perante novos desafios, cada vez mais condicionados aos interesses fluídos dos consumidores. A marca é um elemento crescentemente importante e a sua gestão é transversal aos vários processos de uma empresa, merecendo uma maior atenção como elemento gerador de uma relação com o consumidor (KAPFERER, 2001; AAKER, 1991; ATKIN, 2008).

Para além da questão do brand awareness (KAPFERER, 2001), importa sublinhar as narrativas culturais impressas nos objetos e na comunicação associados à marca que, através dos elementos simbólicos e às associações criadas, criam o discurso e a base para uma relação com o consumidor. A análise do contexto cultural e das tendências de mentalidade e de consumo permite antever a reação do público à marca e desenvolver discursos que possam ir ao encontro das últimas necessidade e interesses dos segmentos alvo. A questão cultural assume, assim, uma importância crescente e tornase alvo de atenção na geração de inovação e de uma estratégia integrada para a marca. Nas empresas, estamos perante a inovação cultural quando uma marca é capaz de oferecer uma expressão cultural com um cunho inovador. Para explicar esta questão, recorremos às ideias de Douglas Holt e de Douglas Cameron (2010, p. 173), na medida em que os autores sugerem que algumas das marcas mais valiosas e com poder no mundo tornaram-se referências por oferecerem uma expressão cultural inovadora. $\mathrm{O}$ coolhunter e o analista de tendências desenvolvem um papel da maior importância na identificação de pistas de inovação e de pontos de contacto possíveis entre a marca, a cultura e o público. O próprio conceito de inovação prende-se com as expressões culturais que não são mais do que reflexos das mutações nos quadros socioculturais e nas mentalidades grupais e individuais, visíveis 
em padrões, ou tendências. Por outras palavras, de modo a compreender e a gerar inovação, torna-se necessário compreender e estudar não só o papel da cultura e da sua visibilidade, mas também as suas manifestações, estruturas e processos.

As manifestações culturais não só proporcionam um quadro rico sobre a composição social, como regulam elementos de pertença, de reconhecimento e de alavancagem social. Tal como Michael Solomon (1999, p. 495-496) sugere, as escolhas de consumo não podem ser compreendidas sem considerar o contexto cultural em que são criadas, ou seja, a cultura é a lente através da qual as pessoas observam os produtos. As marcas, ao criarem associações simbólicas a determinados produtos ou serviços, criam uma narrativa, ou uma expressão cultural, capaz de se tornar um agente e um meme - termo utilizado por Richard Dawkins (2006) -, os quais são fatores complexos para a criação de sentidos e para a regulação das relações grupais e individuais.

Com base nestes pressupostos, e considerando um mundo onde os grupos e as tribos são cada vez mais diversos e compostos por indivíduos com identidades e características divergentes, o branding não se pode orientar por estratégias capazes de alienar uma grande parte do seu público-alvo. As estratégias devem ser orientadas para desejos e nichos de forma objetiva e transparente. A assimilação cultural de indivíduos, mantendo traços originais da sua cultura de origem é uma realidade que também não pode ser ignorada. Todavia, a grande proliferação de símbolos, de imagens e de representações torna cada vez mais difícil a correta identificação e definição de uma cultura ou identidade. Os valores podem ser elementos capazes de criar uma comunicação que apele aos vários grupos e nichos. Não obstante, o foco do marketing e do branding deve manter-se na objetividade dos benefícios e numa comunicação transparente capaz de apelar a grupos cada vez mais críticos e com mais informações, que não são influenciados pela comunicação do mesmo modo como eram anteriormente. As tendências de mentalidade e de comportamento de consumo dão pistas e fornecem caminhos sobre as mentalidades que influenciam os consumidores e quais são os seus atuais padrões de consumo, práticas e representações que podem funcionar como elementos a explorar na criação de estratégias de marketing e de branding. 


\section{CONSIDERAÇÕES FINAIS}

A nova realidade sociocultural presente na segunda década do século XXI pressupõe uma reformulação fluída de estruturas, de mentalidades e de comportamentos. As tendências de comportamento de consumo são fenómenos sociais que traduzem estas alterações e que tornam visíveis os processos e as estruturas invisíveis que permeiam a natureza social.

A esfera de influência das tendências de mentalidade ajuda a compor o quadro complexo dos comportamentos relacionados com o quotidiano e os vários estilos de vida Este largo campo de influência possui um grande potencial de análise e de aplicação e atrai a atenção das marcas que o explora como um meio para investigar e promover determinadas práticas.

Nestesentido, esteartigoarticuloualgumas dasvisõesmais reconhecidas sobre o estudo das tendências de mentalidade e de comportamento de consumo, promovendo um quadro contextual e científico do estado da arte que, em articulação com outras áreas, permita um estudo sociocultural das marcas e do seu contexto, o qual pode ser aprofundado no desenvolvimento de estudos sobre estratégia e comunicação de marcas. Esta delimitação do campo dos estudos de tendências e do coolhunting foi basilar para a problematização consequente sobre o branding e como devemos abordar as suas estratégias. A problematização e relação entre áreas do marketing e dos estudos da cultura, ou seja, das ciências do consumo e das humanidades, sublinha uma nova perspetiva interdisciplinar que pretende gerar novas visões e soluções que já não conseguem surgir apenas de um ramo específico do conhecimento. As humanidades são agora um campo novo a explorar pelas ciências empresariais e do consumo que encontram no estudo da cultura novos dados que complementam os estudos de outras disciplinas, tal como as investigações sobre as marcas e os estudo de mercado.

Como resultado, numa perspetiva de análise do impacto para a ciência e inovação, surgem novas práticas e visões associados à gestão das marcas que sublinham a relevância do estudo da cultura e das mentalidades, bem como das suas manifestações no quadro social, alargando o número de ferramentas disponíveis aos profissionais e investigadores do branding. A emergência da nova disciplina dos Estudos de Tendências e do Coolhunting contribuem para o estudo do consumidor e para delinear estratégias com maior segurança. A gestão de marcas, cada vez mais, deve ser uma tarefa 
capaz de gerir as grandes alterações nos comportamentos, implementando narrativas que reflitam as novas mentalidades, necessidades e interesses do consumidor. A marca não só representa uma segurança face à qualidade e atributos esperados, mas também determinadas associações a imaginários socialmente construídos. O consumidor está cada vez mais informado e preocupa-se com a sua imagem pessoal, seja real ou virtual, e com a forma como os outros o percecionam. As marcas devem contribuir para a construção de uma narrativa, sendo um reflexo dos interesses e dos gostos do público. Neste sentido, deve funcionar como um símbolo e uma representação de uma cultura que se encontra integrada em códigos novos e socialmente complexos, mas também em constante reconstrução. Só assim, a marca consegue criar uma relação com o consumidor e manter-se relevante num mundo cada vez mais plural e em constante mutação.

Este artigo apresenta-se como uma introdução aos estudos de tendências e ao seu contributo, bem como da análise cultural para a gestão de marcas. Torna-se necessário abordar e aprofundar futuramente modelos e articulações específicas entre as áreas, de modo a permitir uma ativação real do conhecimento ao nível do branding. Permanece também por explorar, em sede de investigações futuras, a relação das marcas com um terreno cultural que, para além de multicultural, é crescentemente plural, transcultural e, também, mais incerto.

\section{NOTAS}

[1] Trecho original: "We have defined "coolness" as a property combined of four characteristics. First, cool things are fresh and new. [...]. Second, cool things make us part of a community, they help us to be with "people like us". [...] Third, cool things are fun. Owning an iPhone is fun, because it looks so well-designed and cool. [...] Fourth, cool things give meaning to our life. Cool things make people happier and feel good" (Gloor et al, 2009, p. 1-2).

[2] Trecho original: "The Trendsetters are the most open and curious individuals with regard to style and taste [...] The trend followers are a bit like the trendsetters, but they need to have seen other people use 
the innovative new styles before themselves will use them. [...] Early mainstreamers accept new styles just before the majority [...] Mainstreamers are average in their acceptance of new, innovative styles [...] Conservatives prefer styles that have existed for years or even decades. They are the people who are the most skeptical of new styles" (VEJLGAARD, 1998, p. 7172).

[3] Trecho original: "The speed of consumer and product change, the blurring of traditional demographics boundaries, the growing power of the consumer and the nature of globalism are all making trend determination a necessity. Trends can help companies make sense of their market in time of change" (HIGHAM, 2009, p. 17).

\section{REFERÊNCIAS BIBLIOGRÁFICAS}

AAKER, David. Managing Brand Equity. New York: The Free Press, 1991. ATKIN, Douglas. 0 Culto das Marcas. Quando os consumidores se tornam verdadeiros crentes. Tradução de Luís Jorge, Lisboa:Tinta da China, 2008.

DAWKINS, Richard. The Selfish Gene. Oxford: Oxford University Press, 2006 [1976].

GLADWELL, Malcolm. The Tipping Point: How little things can make a big difference. New York: Little Brown, 2006.

GLOOR, Peter et al. "Coolfarming - How Cool People Create Cool Trends". 2009.

Disponível em http://www.ickn.org/documents/edumedia09_coolfarming. pdf. Acesso em 28/04/2012.

GOMES, Nelson; FRANCISCO, Ana. Introdução aos Estudos de Tendências: Conceitos e Modelos. Lisboa:Trends Research Center, 2013.

HIGHAM, William. The Next Big Thing. London: Kogan Page, 2009.

HOLT, Douglas; DOUGLAS, Cameron. Cultural Strategy: using innovative ideologies to build breakthrough brands. Oxford: Oxford University Press, 2010.

KAPFERER, Jean-Noel. [re]inventing the brand. Tradução de Anglia Translations, London: Kogan Page, 2001.

KAPFERER, Jean-Noel. O que vai mudar as marcas. Tradução de Carolina Huang, Porto Alegre: Bookman, 2004. 
LIPOVETSKY, Gilles. A Felicidade Paradoxal: Ensaio sobre a sociedade do Hiperconsumo. Traduzido por Patrícia Xavier, Lisboa: Edições 70, 2006.

SOLOMON, Michael. Consumer Behavior. $4^{\mathrm{a}}$ edição, New Jersey: Prentice Hall, 1999.

RASQUILHA, Luís. Tendências e Gestão da Inovação. Lisboa: Verlag Dashofer, 2011.

VEJLGAARD, Henrik. Anatomy of a Trend. New York: McGraw-Hill, 2008.

SCIENCE OF THE TIME - http://www.scienceofthetime.com. Acesso em 0602-2015.

Recebido em: 08/02/2014; Aceito em: 12/04/2014.

Esta obra foi licenciada com uma Licença Creative Commons.
Nelson Pinheiro Gomes é docente no Programa de Cultura e Comunicação da Faculdade de Letras da Universidade de Lisboa, sendo Co-coordenador da Pós-Graduação de Especialização em Comunicação de Tendências. Acumula a responsabilidade da direção científica do Trends Research Center. Possui um Doutoramento na especialidade de Cultura e Comunicação (com uma tese sobre Estudos de Tendências) e um Mestrado em Ciências da Cultura, ambos pela Universidade de Lisboa; um MBAMaster em Gestão de Empresa e especializações em Moda, Economias e Políticas Urbanas, Coolhunting e Gestão da Inovação, Políticas Europeias, entre outras. É investigador no CEAUL (Centro de Estudos Anglísticos da Universidade de Lisboa). No âmbito de uma articulação próxima entre as áreas das Humanidades e das Ciências Sociais (ou até das Humanidades Aplicadas), tem vindo a desenvolver investigação e atividades profissionais no campo dos Estudos de Tendências, com foco nas disciplinas de Cultura de Consumo e de Cultura da Moda. 